\title{
Does healthcare personnel responsible for epidemiological surveillance know how to identify mandatorily notifiable diseases?
}

\author{
Yamily Yrigoín-Pérez, ${ }^{1}$ Cristian Díaz-Vélez ${ }^{2}$ and Moisés Apolaya-Segura ${ }^{3}$ \\ ${ }^{1}$ Sociedad Científica de Estudiantes de Medicina Veritas SCIEMVE; 'Sanitary Intelligence Office, Hospital Nacional Almanzor Aguinaga Asenjo \\ EsSalud; '3niversidad de San Martín de Porres, Center of Clinical Epidemiology and Evidence-based Medicine Research, Chiclayo, Peru
}

Dear editor,

In response to the article by Lugo-Caballero et al. ${ }^{1}$ about knowledge on vector-transmitted diseases (dengue, rickettsiosis and Chagas disease) by physicians, where $62.5 \%$ of physicians are described to have moderate knowledge, $37.5 \%$ poor knowledge and $0 \%$ adequate, I'll allow myself some remarks on the subject.

Epidemiologic surveillance of infectious diseases and harm that are subject to mandatory notification is crucial to the planning, implementation and evaluation of programs for the prevention and control of diseases, as well as to identify the most compromised regions and population groups. ${ }^{2,3}$ It depends on the definition of the case, recognition of the disease, collection of individual data, notification and analysis for opportune detection of outbreaks with the purpose to control the impact on the population. ${ }^{3}$ The process of epidemiological surveillance requires health personnel trained to submit a detailed or abridged report of diseases that have to be mandatorily notified to the relevant authorities. ${ }^{2}$

Studies carried out in different parts of the world have demonstrated that one out of every two persons felt informed about the obligation to notify; however, they did it incompletely. The most common causes for not complying with information requirements include the lack of knowledge on when to inform -not being sure that the diagnosed disease is reportable-, negative attitude towards reports and lack of motivation due to inadequate feedback. ${ }^{3-5}$

Currently, in Peru there are 19 infectious diseases subject to epidemiological surveillance, out of which
12 have been reported in the Lambayeque region. ${ }^{6}$ Most members of health personnel obtain their knowledge from TV programs, internet and other colleagues' experiences; however, reports indicate that $50 \%$ have deficient knowledge on epidemiological surveillance. ${ }^{3}$

Peruvian Social Security has a coverage of approximately $34 \%$ of the national population and, in September 2018, the annual national meeting was carried out with those responsible of the 33 networks that integrate the epidemiological surveillance system, who were applied the "Knowledge" section of the Knowledge on Epidemiological Surveillance, Attitudes towards Epidemiological Notification and Experience in the Reporting of Notifiable Diseases Questionnaire (validated by experts and with KR-20 of 0.71 for knowledge and Cronbach's alpha of 0.76 for attitudes). ${ }^{8}$ This questionnaire poses 12 questions, scenarios and problem-cases to identify mandatory report diseases. It was self-administered and answered by 36 health professionals (Table 1).

The results showed that most personnel responsible for epidemiological surveillance had received training; however, only $5.5 \%$ answered the questionnaire correctly and more than $50 \%$ had 8 or less correct answers.

Since 2013, reports of cases of dengue have increased. In 2014, there was warning for measles and rubella, owing to increased population flow between countries: in 2015, one case of measles imported from Germany, chikungunya imported cases and the first autochthonous case of the latter were reported; cases of human rabies and canine rabies dissemination in the Puno and Arequipa department were also reported. On that same year, an increased risk of influenza and other
Correspondence:

Cristian Díaz-Vélez

E-mail: cristiandiazv@ hotmail.com
Date of reception: 12-02-2018

Date of acceptance: 13-02-2018

DOI://dx.doi.org/10.24875/GMM.M18000153
Gac Med Mex. 2018;154:290-291

Contents available at PubMed

www.gacetamedicademexico.com 
Table 1. Knowledge on epidemiological surveillance and mandatory reporting of infectious diseases procedures by health personnel $(n=36)$

\begin{tabular}{lcc}
\hline Characteristic & $\mathbf{n}$ & $\%$ \\
\hline Training on epidemiological surveillance & & \\
Yes & 25 & 69.4 \\
No & 11 & 30.6 \\
Frequency of answers for each question of the applied & & \\
questionnaire & 2 & 5.5 \\
10 correct answers & 3 & 8.3 \\
9 correct answers & 12 & 33.3 \\
8 correct answers & 10 & 27.8 \\
7 correct answers & 4 & 11.1 \\
6 correct answers & 3 & 8.3 \\
5 correct answers & 2 & 5.6 \\
Recognition of clinical cases & & \\
Mandatory notifiable disease & 31 & 86.1 \\
Dengue & 29 & 85.6 \\
Cholera & 35 & 97.2 \\
Malaria & 5 & 13.9 \\
Rubella & 12 & 33.3 \\
Pneumonic plague & 29 & 80.6 \\
Poliomyelitis & 35 & 97.2 \\
& & \\
Actions when a notifiable case is identified & & \\
Makes the mandatory report & 5 & 13.9 \\
Identifies who is responsible for making the & 12 & 33.3 \\
mandatory report in the health center & 26 & 72.2 \\
Identifies international notification report & 36 & 100.0 \\
Recognizes epidemiologic link & & \\
\hline
\end{tabular}

respiratory viruses' transmission was informed in approximately $12.8 \%$ (http://www.dge.gob.pe/salasituacional). During 2017, several outbreaks of dengue, malaria, zika, chikungunya, bubonic plague and other diseases subject to epidemiological surveillance have been identified in Peru. ${ }^{6,8}$

According to the referred survey, there was higher recognition deficit for malaria (84\%), rubella (67\%), dengue (19\%) and pneumonic plague (19\%); when comparing the results with statistics, we can affirm that there is an underestimated number of cases of mandatory notifiable infectious diseases and, therefore, of unidentified outbreaks. ${ }^{6,8}$
Moreover, it became evident that only $13.9 \%$ of surveyed subjects used to make the mandatory report, and $33.3 \%$ recognized those who were responsible for making the mandatory report in their health establishments, a fact that may be related to the causes found by Nader et al.., ${ }^{2}$ Tan et al. ${ }^{5}$ and Mera et al. ${ }^{3}$

The delay in the identification of infectious diseases that are under epidemiological surveillance leads to Peruvian Ministry of Health intervention being suboptimal, with outbreaks and epidemics appearing that can cause the death of numerous people; therefore, it is important for the personnel in charge of health posts to be in constant training and updating for opportune recognition of infectious diseases that are subject to epidemiological surveillance and to know the correct form to carry out the mandatory report.

\section{References}

1. Lugo-Caballero Cl, Dzul-Rosado K, Dzul-Tut I, Balam-May Á, Zav-la-Castro J. Conocimiento de enfermedades transmitidas por vectores (dengue, rickettsiosis y enfermedad de Chagas) en médicos. Gac Med Mex. 2017; 153:321-328

2. Nader F, Askarian M. How do Iranian physicians report notifiable diseases? The first report from Iran. Am J Infect Control. 2009;37(6):500-504.

3. Mera-Muguerza C, Díaz-Vélez C. Nivel de conocimientos y actitudes sobre proceso de vigilancia epidemiológica y notificación obligatoria de enfermedades infecciosas en personal de salud en primer nivel en la provincia de Chiclayo [Tesis para obtener el título profesional de médico cirujano]. Perú: Universidad de San Martín de Porres; 2017.

4. Nnebue CC, Onwasigwe CN, Adogu POU, Onyeonoro UU. Awareness and knowledge of disease surveillance and notification by health-care workers and availability of facility records in Anambra state, Nigeria. Niger Med J J Niger Med Assoc. octubre de 2012;53(4):220-5.

5. Hsiu-Fen T, Chia-Yu Y, Hsueh-Wei C, Chen-Kang C, Hung-Fu Tseng. Private doctors' practices, knowledge, and attitude to reporting of communicable diseases: a national survey in Taiwan. BMC Infect Dis. 2009;9:11.

6. Ministerio de Salud. Boletín Epidemiológico del Perú. Perú: Ministerio de Salud; 2017.

7. EsSalud. Características demográficas, sociales, económicas y acceso a los servicios de salud de la población asegurada a EsSalud, 2015. Perú: Seguro Social de Salud; 2015.

8. Centro Nacional de Epidemiología, Prevención y Control de Enfermedades. [Sitio web]. Alertas epidemiológicas 2017. [Actualizado 2018]. Perú: Ministerio de Salud; Disponible en: http://www.cdc.gob.pe/portal/ index.php?option=com_content\&view=article\&id=448. 